Gut, 1976, 17, 144-146

\title{
Relationship of serum gastrin response to lower oesophageal sphincter pressure
}

\section{J. DENT AND J. HANSKY}

From the Monash University Department of Medicine, Prince Henry's Hospital, Melbourne, Victoria, Australia

SUMMARY The role of gastrin in controlling lower oesophageal sphincter pressure (LESP) has been examined by measurement of LESP and serum gastrin response to a test protein solution and a control solution in humans. Both solutions were associated with significant $(P<0.005)$ rise in LESP, but serum gastrin rose significantly $(P=0.05)$ only after the protein solution. The rise in serum gastrin after the protein solution preceded the rise in LESP by 30 minutes. These results suggest that the lower oesophageal sphincter response to feeding may be independent of protein and is unrelated to gastrin release.

Exogenous gastrin is a powerful stimulant of lower oesophageal sphincter (LES) contraction (Giles et al., 1969). Castell and Harris (1970) proposed that endogenous gastrin is a major controller of basal lower oesophageal sphincter pressure (LESP) on the basis of observed LESP changes with alteration of intragastric $\mathrm{pH}$. Changes in circulating gastrin with $\mathrm{pH}$ manipulation were assumed in this study, as they were with protein feeding experiments in man in which a rise in LESP occurred after feeding (Nebel and Castell, 1972; Lipshutz et al., 1973; Roszkowski et al., 1973).

Closer examination of this theory with gastrin radioimmunoassay has not supported gastrin as the mediator of the gastric pH dependent LESP changes (Higgs et al., 1974). With the protein associated rise in LESP, McCall et al. (1975) reported good correlation and Morris et al. (1974) poor correlation with serum gastrin levels.

The aim of this study was to examine the relationship of serum gastrin and LESP responses to a test protein solution and a control isosmotic saline solution.

\section{Methods}

Nineteen normal healthy volunteers, 14 men and five women of mean age 21 years were studied after a minimum fast of five hours.

The manometric catheter was passed orally or nasally after spray anaesthetization of the oropharynx with $3 \mathrm{ml} 2 \%$ lignocaine. The subject then Received for publication 14 November 1975 remained supine for the duration of the study. After a 20 minute rest period the study was commenced. An indwelling venous needle was kept patent with heparin $50 \mathrm{u} / \mathrm{ml}$ and used to sample blood at the beginning of the study and subsequently every 15 minutes for the next $2 \frac{1}{2}$ hours.

Thirty minutes after the start of the study, the solution was given via the gastric channel of the manometric catheter. This was either a control solution consisting of $200 \mathrm{ml}$ sodium chloride $47 \mathrm{~g} / \mathrm{l}$ pH 6.5 or a test solution of two Oxo cubes dissolved in $120 \mathrm{ml}$ molar glycine with $50 \mathrm{ml}$ molar sodium bicarbonate, made up to $200 \mathrm{ml}, \mathrm{pH} \mathrm{7 \cdot 0}$. Both solutions were given at $37^{\circ} \mathrm{C}$ and had osmolarities of $1500 \mathrm{mmol} / \mathrm{l}$.

Lower oesophageal sphincter pressure was measured by constant perfusion manometry. The first 11 studies were done using a conventional triple lumen PVC catheter with each lumen $1.5 \mathrm{~mm}$ internal diameter and side holes $5 \mathrm{~cm}$ apart. LESP was measured at the start of observations and subsequently every 15 minutes for $2 \frac{1}{2}$ hours by pull through. The last eight studies were done with a six lumen PVC catheter, with four side holes $5 \mathrm{~mm}$ apart which were positioned within the LES and sampled regularly to determine maximal LESP; gastric and oesophageal pressures were recorded by the other two channels.

The manometric channels were perfused by two syringe pumps at $0.9 \mathrm{ml} / \mathrm{min}$. Pressures were recorded with Statham transducers and Hewlett Packard carrier amplifiers onto three channels of a four channel direct writing Brush Recorder. 
Respiration, signalled by a strain gauge around the thorax, was recorded on the fourth channel.

The manometric tracings were interpreted without knowledge of their identity by one observer (J.D.). End expiratory pressure was taken with intragastric pressure as the reference. Major dynamic influences on LESP were excluded by not analysing the trace within 30 seconds of lower oesophageal peristalsis or during or 30 seconds after gastric contraction greater than $0.67 \mathrm{kPa}(5 \mathrm{mmHg})$.

Basal sphincter pressure was taken as the mean of the measurements during the 30 minutes before the meal. Subsequent pressure changes were expressed as a percentage of the basal figure. Serum for gastrin estimation was stored at $-4^{\circ} \mathrm{C}$ till assayed in duplicate by radioimmunoassay (Hansky and Cain, 1969). An antibody that cross reacts equally with all known molecular forms of gastrin was used and mono-iodinated gastrin tracer was prepared by the method of Stadil and Rehfeld (1972). Basal serum gastrin was the mean of the three samples taken before feeding, and all gastrin levels were expressed as picograms $/ \mathrm{ml}$.

\section{Results}

The table indicates the numbers in test and control groups according to the manometric technique used. Results from the two techniques were pooled and analysed with respect to mean serum gastrin and mean percentage charge in LESP from basal with time.

\begin{tabular}{llll}
\hline \multirow{2}{*}{ Solution } & \multicolumn{3}{l}{ Manometric technique } \\
\cline { 2 - 4 } & Pull through & Multi-lumen & Total \\
\hline Test & 6 & 4 & 10 \\
Control & 5 & 4 & 9 \\
\hline
\end{tabular}

Table Numbers in each group according to manometric technique

The test solution group showed significant rise in peak serum gastrin above basal $(P=0.05)$. This response was established 15 minutes after feeding and was sustained with a small peak at 75 minutes followed by a gradual drop (Fig. 1). The control group did not show any significant change in peak serum gastrin above basal $(P=0 \cdot 10)$.

Peak LESP was significantly elevated over basal in both test $(P<0.005)$ and control $(P<0.005)$ groups. There was no significant difference between the magnitude of the peaks between the two groups, although there was a difference in the timing of these peaks as shown on Fig. 2.

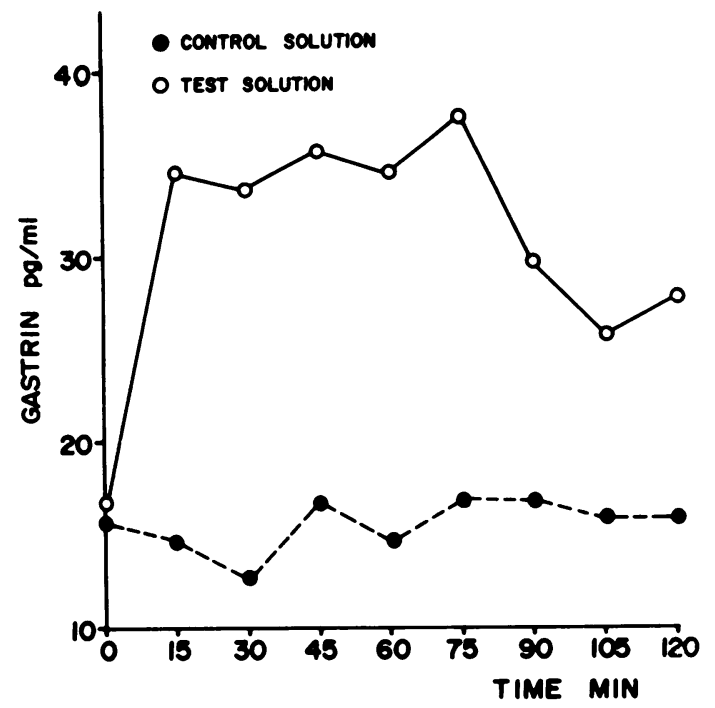

Fig. 1 Serum gastrin response to test and control solutions.

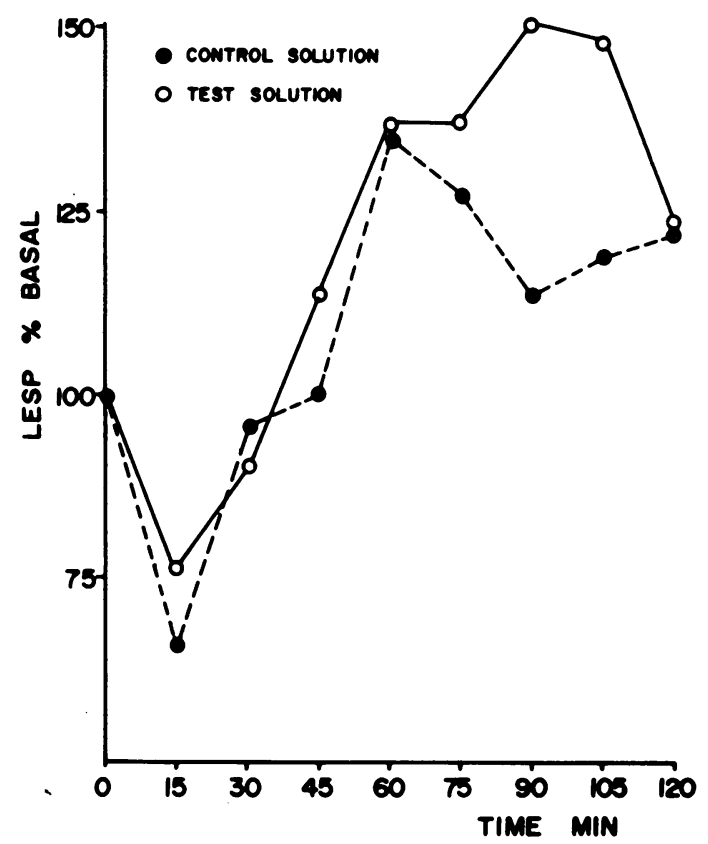

Fig.2 Lower oesophageal sphincter response to test and control solutions.

\section{Discussion}

Both control and test solutions were associated with similar significant sustained rise in LESP, though serum gastrin rose significantly only after the test solution. This dissociation of serum gastrin and 
LESP after the test solution militates against gastrin being a major controller of LESP. It also suggests that the rise in LESP after the protein solution could be independent of its protein content and due to some factor common to the two solutions. McCall et al. (1975) used a similar though lower molarity protein solution, but did not use a control. Their conclusion that the pressure rise they obtained, which was very similar to this study, was mediated by gastrin is invalid, since it relies on the assumption that gastrin release was the only way in which the solution could affect LESP.

The time lag between gastrin and LESP responses was 30 minutes in this study and 20 minutes in that of McCall et al. (1975). This temporal dissociation is further evidence that the rise in serum gastrin is not the major mediator of LESP response after a protein solution, since exogenous gastrin has an immediate effect on LESP. Thus the time lag cannot be explained by a time consuming gastrin-receptor interraction as suggested by McCall et al. (1975).

Explanations for food and $\mathrm{pH}$ evoked LES responses have been sought mainly from within the stomach. Most of the stimuli have been liquid and likely to enter the duodenum in significant amounts during the study period. This could lead to superimposition of duodenal hormonal and neural influences on the pattern of LES responses. The significance of these mechanisms in relation to LES activity is not well defined and measurement or control of these factors is very difficult or impossible. Considerably more experimentation with more rigorous control of the stimuli and estimation of serum gastrin and secretin and cholecystokinin if possible, is needed before a balanced view of the importance of hormonal control of LES function can be gained.

The financial support of the Australian National Health and Medical Research Council is gratefully acknowledged.

\section{References}

Castell, D. O., and Harris, L. D. (1970). Hormonal control of gastroesophageal sphincter strength. New England Journal of Medicine, 282, 886-889.

Giles, G. R., Mason, M. C., Humphries, C., and Clark, C. G. (1969). Action of gastrin on the lower oesophageal sphincter in man. Gut, 10, 730-734.

Hansky, J., and Cain, M. D. (1969). Radioimmunoassay of gastrin in human serum. Lancet, 2, 1388-1390.

Higgs, R. H., Smyth, R. D., and Castell, D. O. (1974). Gastric alkalinization. Effect on lower esophageal sphincter pressure and serum gastrin. New England Journal of Medicine, 291, 486-490.

Lipshutz, W. H., Gaskins, R. D., Lukash, W. M., and Sode, J. (1973). Pathogenesis of lower esophageal sphincter incompetence. New England Journal of Medicine, 289, 182-184.

McCall, I. W., Harvey, R. F., Owens, C. J., and Clendinnen, B. G. (1975). Relationship between changes in plasma gastrin and lower oesophageal sphincter pressure after meals. British Journal of Surgery, 62, 15-18.

Morris, D. W., Schoen, H., Brooks, F. P., and Cohen, S. (1974). Relationship of serum gastrin and lower esophageal sphincter pressure in normals and patients with antrectomy. Gastroenterology, 66, A96/750.

Nebel, O. T., and Castell, D. O. (1972). Lower esophageal sphincter pressure changes after food ingestion. Gastroenterology, 63, 778-783.

Roszkowski, A., Guillou, P., and Giles, G. R. (1973). The response of the lower oesophageal sphincter to a test meal stimulus. British Journal of Surgery, 60, 489-493.

Stadil, F., and Rehfeld, J. F. (1972). Preparation of ${ }^{125} \mathrm{I}$ labelled synthetic human gastrin I for radioimmunoanalysis. Scandinavian Journal of Clinical and Laboratory Investigation, 30, 361-368. 